\title{
Fluticasone-formoterol: a systematic review of its potential role in the treatment of asthma
}

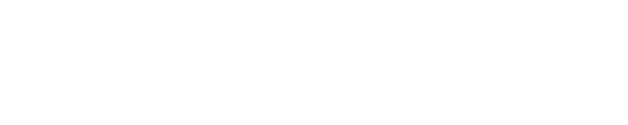

\author{
Theresa R Prosser \\ Suzanne G Bollmeier \\ St Louis College of Pharmacy, \\ St Louis, MO, USA
}

Correspondence: Suzanne G Bollmeier St Louis College of Pharmacy, 4588 Parkview Place, St Louis, MO 63I I0, USA Tel + I 3 I 44468525

Fax + I 3 I 4468500

Email sbollmeier@stlcop.edu
Background: The purpose of this systematic review is to summarize and evaluate the available published data regarding the efficacy and safety of a combination product containing fluticasone propionate/formoterol (FP-F) in order to establish its potential role compared with other inhaled combination corticosteroid/long-acting beta ${ }_{2}$ receptor agonists for the maintenance treatment of asthma.

Methods: A PubMed and EMBASE search was conducted using the terms "fluticasone propionate", "formoterol fumarate", "Flutiform ${ }^{\circledR}$ ", and "asthma" in July 2014 to identify trials using this combination specifically for the treatment of asthma. Additional information was gathered from references cited in the identified publications, the package insert, and the ClinicalTrials. gov registry. All randomized controlled clinical trials for humans in asthma were evaluated for inclusion. Data from animal trials, clinical trials for chronic obstructive pulmonary disease, and non-English sources were excluded.

Results: Seven short-term safety and efficacy trials of FP-F compared with its individual components and two comparison trials of FP-F versus other combination products were identified. Generally, the incidence of drug-related adverse events was low and consistent with previously reported drug class-related adverse events (ie, pharyngitis, dysphonia, and headache). The combination of FP-F was shown to be noninferior to fluticasone propionate/salmeterol for improving predose forced expiratory volume at one second $\left(\mathrm{FEV}_{1}\right)$ and 2 hours post dose $\mathrm{FEV}_{1}$. FP-F was also noninferior to budesonide/formoterol in improving predose $\mathrm{FEV}_{1}$. Other clinical endpoints, including various symptom scores, asthma control, quality of life, and subjects' assessment of the medications were not significantly different.

Conclusion: Poor asthma control is common. The data from short-term studies indicate that this inhaled corticosteroid and long-acting beta ${ }_{2}$ receptor agonist combination product is noninferior to similar combination products available. As FP-F is available in different strengths, the corticosteroid dose can be titrated without changing devices. A potential advantage is that those with good technique, the same type of device could be used for both their controller and rapid relief inhaler medicines. The choice of this combination versus other similar products may be based primarily on cost.

Keywords: fluticasone-formoterol, asthma, inhaled corticosteroids, long-acting beta receptor agonists, Flutiform ${ }^{\mathbb{R}}$

\section{Challenges to optimally controlling and managing asthma}

Asthma is a world-wide problem affecting an estimated 300 million people. ${ }^{1}$ The prevalence of asthma varies widely throughout the world from less than $2 \%$ in some countries (eg, Greece and the People's Republic of China) to over 10\% in others (Australia, Vietnam, UK, USA). Part of the variation in prevalence could be due to the lack of uniform criteria for diagnosing asthma. The prevalence of asthma is increasing in many areas, including Africa, Latin America, Eastern Europe, Asia, and the USA. 
For example, the prevalence of asthma increased in the USA by $14.8 \%$ in less than 10 years $(2001-2010){ }^{2}$

Asthma is a major health issue worldwide not only because of its prevalence, but also its impact on morbidity and mortality. The World Health Organization estimates 13.8 billion disability-adjust life years each year related to asthma. ${ }^{3}$ Approximately 346,000 deaths worldwide are attributed to asthma annually. ${ }^{3}$ The economic impact of asthma is quite large, including both direct costs, eg, medication and routine and urgent care, and indirect costs, eg, decreased quality of life and productivity, and missed school/work days. ${ }^{1}$

Adequacy of asthma control is assessed by a combination of symptom frequency and risk for future poor asthma outcomes. ${ }^{4}$ Control of symptoms is defined by a frequency of daytime symptoms and rapid reliever use of less than twice weekly and an absence of night-time symptoms and activity limitations. ${ }^{4}$ Risk for poor outcomes includes excessive rapid reliever use (ie, more than 200 doses/month), poor controller adherence (often defined as taking less than $80 \%$ of prescribed doses per month), incorrect device technique, and decreased lung function, eg, forced expiratory volume at one second $\left(\mathrm{FEV}_{1}\right)$ less than $80 \%$ of predicted or personal best.

Both the Global Initiative for Asthma $^{3}$ and National Asthma Education and Prevention ${ }^{4}$ guidelines recommend inhaled corticosteroids (ICS) as first-line long-term controller therapy for persistent asthma to decrease airway inflammation. For persistent asthma not controlled by low-dose ICS therapy alone, adding a long-acting beta ${ }_{2}$ receptor agonist (LABA) can be an alternative to increasing to a moderate dose of the ICS. Combining an ICS and a LABA into a single device increases patient convenience and potentially adherence. There is little benefit to further increases in the dose of LABAs because the dose-bronchodilation response curve is fairly flat; ${ }^{5}$ that is, further increases in dose result in minimal incremental bronchodilation. Therefore, the dose of LABAs in these combination products is often constant; a further step-up in therapy is usually accomplished by additional increases in the dosage of the ICS component (see examples of such combination products in Table 1 and a comparison of ICS doses in Table 2). In addition to a controller medication, patients are usually prescribed an inhaled short-acting beta ${ }_{2}$ receptor agonist to use as needed for rapid relief of symptoms. ${ }^{3,4}$

Asthma can often be controlled with appropriate medications, but poorly controlled asthma is still quite common. Reasons for poor control vary by patient and are likely multifactorial, including chronic exposure to triggers, lack of asthma action plans to deal with acute symptoms, poor
Table I Examples of ICS-LABA combination products and devices ${ }^{\mathrm{a}}$

\begin{tabular}{|c|c|c|}
\hline Drug (brand name) & Type of device & $\begin{array}{l}\text { Strength(s) } \mu \mathrm{g} \\
\text { ICS/LABA }\end{array}$ \\
\hline BEC-F & MDI & $100 / 6$ \\
\hline \multirow[t]{5}{*}{ BUD-F (Symbicort ${ }^{\circledR}$ ) } & DPI (Turbuhaler $\left.{ }^{\circledR}\right)$ & $100 / 6$ \\
\hline & & $200 / 6$ \\
\hline & & $400 / 12$ \\
\hline & HFA MDI & $80 / 4.5$ \\
\hline & & $160 / 4.5$ \\
\hline $\mathrm{FF}-\mathrm{V}\left(\mathrm{Breo}^{\circledR}\right)$ & DPI (Ellipta $\left.{ }^{\circledR}\right)$ & $100 / 25$ \\
\hline \multirow[t]{6}{*}{ FP-S $\left(\right.$ Advair $^{\circledR}$, Seretide $\left.^{\circledR}\right)$} & DPI (Diskus $\left.{ }^{\circledR}\right)$ & $100 / 50$ \\
\hline & & $250 / 50$ \\
\hline & & $500 / 50$ \\
\hline & HFA MDI & $45 / 21$ \\
\hline & & || $5 / 2 \mid$ \\
\hline & & $230 / 21$ \\
\hline \multirow[t]{3}{*}{ FP-F (Flutiform ${ }^{\circledR}$ ) } & HFA-MDI & $50 / 5$ \\
\hline & & $125 / 5$ \\
\hline & & $250 / 10$ \\
\hline \multirow[t]{2}{*}{ MM-F (Dulera $\left.{ }^{\circledR}\right)$} & HFA MDI & $100 / 5$ \\
\hline & & $200 / 5$ \\
\hline
\end{tabular}

Note: aProduct availability and strengths may vary by country.

Abbreviations: BEC, beclomethasone; BUD, budesonide; DPI, dry powder inhaler; $\mathrm{F}$, formoterol; FF, fluticasone furoate; FP, fluticasone propionate; ICS, inhaled corticosteroids; LABA, long-acting beta ${ }_{2}$ receptor agonist; MM, mometasone; HFA MDI, hydrofluoroalkane metered-dose inhaler; S, salmeterol; V, vilanterol.

perception by patients of symptoms that indicate poor control, and poor adherence. ${ }^{6}$ Nonadherence with daily controller medications is very common, and increases the risk of poor outcomes and results in additional health care costs. In a review of ten studies, the mean adherence rate with controller medications was only $48 \%$. $^{7}$ An analysis of electronic prescription and filled claims data revealed that almost onequarter of first-time prescriptions for controller medications were never picked up or started (ie, primary nonadherence). ${ }^{8}$ More than $50 \%$ of US adults in one large study did not refill a

Table 2 Comparison of ICS doses in adults and children 12 years and older ${ }^{3}$

\begin{tabular}{llll}
\hline ICS & \multicolumn{3}{l}{ Total dose $(\mu \mathrm{g})$ per day } \\
\cline { 2 - 4 } & Low & Medium & High \\
\hline Beclomethasone dipropionate & $200-500$ & $>500-1,000$ & $>1,000$ \\
Beclomethasone & $100-200$ & $>200-400$ & $>400$ \\
Budesonide & $200-400$ & $>400-800$ & $>800$ \\
Ciclesonide & $80-160$ & $>160-320$ & $>320$ \\
Flunisolide & 320 & $>320-640$ & $>640$ \\
Fluticasone propionate DPI & $100-200$ & $>200-400$ & $>400$ \\
Fluticasone propionate HFA & $100-200$ & $>200-500$ & $>500$ \\
Mometasone furoate & $110-220$ & $>220-440$ & $>440$ \\
Triamcinolone acetonide & $400-1,000$ & $>1,000-2,000$ & $>2,000$ \\
\hline
\end{tabular}

Note: From the Global Strategy for Asthma Management and Prevention 2015, () Global Initiative for Asthma (GINA) all rights reserved. Available from http://www. ginasthma.org.

Abbreviations: ICS, inhaled corticosteroids; HFA, hydrofluoroalkane inhaler; DPI, dry powder inhaler. 
controller medicine within 12 months of the initial prescription (ie, secondary nonadherence). ${ }^{7}$ In other studies, a third to half of patients who continue controller medicines either underused them or did not use them as prescribed. ${ }^{8}$ Patients most likely to be adherent are: males older than 35 years and those with comorbidities, moderate to severe asthma, and a low copayment. ${ }^{7}$ The lack of generic products for asthma controller medications generally increases the patients' cost of these agents and so may decrease adherence.

Unfortunately, undertreatment of asthma by providers is significant and also contributes to poor asthma control. In one study, only $55 \%$ of children with persistent asthma were taking a controller medicine. ${ }^{7}$ In part, undertreatment is related to an underestimation of symptoms by both patients and providers. ${ }^{9}$ Poor device technique limits drug delivery to the lungs and lowers efficacy. In studies, $28 \%-68 \%$ of subjects have been reported to not use a metered-dose or dry powder inhaler well enough for the medication to be effective. ${ }^{7}$

The United States Healthy People 2020 Initiative $^{10}$ includes goals to improve asthma outcomes and reduce asthma-related urgent care visits and deaths by increasing the proportion of patients on therapy consistent with asthma guidelines, having written asthma action plans, and receiving formal patient education. Other ways to potentially improve asthma control would be to improve adherence to medications and device technique.

Asthma impacts patients' quality of life and this effect should be assessed periodically. Quality of life for children with asthma has been defined as the measure of emotions, asthma severity, symptoms, urgent care visits, missed school days, and degree of activity limitation. ${ }^{11}$ Various quality of life questionnaires are recommended as part of routine assessment of asthma control. ${ }^{3,4}$ Symptom scores are another method for assessing daily disease impact.

\section{Combination of fluticasone propionate-formoterol fumarate}

A relatively new fixed-dose product combines an ICS, fluticasone propionate (FP), with formoterol fumarate (F), a LABA. Both of these medications have been previously available individually and in combination with other medications (Table 1). This new combination is available in 18 European countries under the name Flutiform ${ }^{\circledR}$ in a pressurized metered-dose inhaler with a hydrofluoroalkane (HFA) propellant. It contains 120 actuations, and is indicated for patients aged 12 years and older with persistent asthma. ${ }^{12}$ This combination (FP-F) is also available (via multiple marketing partners by the manufacturer) in Australia,
Hong Kong, Israel, South Korea, ${ }^{13}$ and Japan. ${ }^{14}$ This systematic review examines the clinical efficacy trials of the FP-F combination, and summarizes the general pharmacologic properties and safety data for the individual components. This information is then integrated to evaluate the potential role of the FP-F combination in the treatment of asthma.

\section{Pharmacology of fluticasone propionate and formoterol fumarate}

Formoterol provides 12 hours of bronchodilation, so it is classified as a LABA. ${ }^{5}$ The duration of action of formoterol is comparable with that of salmeterol; both are used as asthma controller medications in combination with an ICS. The duration of formoterol is longer than that of albuterol, which is usually used as a rapid reliever medication. It is hypothesized that its prolonged duration of action is due to the lipophilic and basic properties of formoterol, which favor formation of a drug depot in the lipid bilayers of airway smooth muscle. Throughout the dosage interval, formoterol leaches out from the depot to interact with the beta receptor. In contrast, salmeterol has a lipophilic "tail" that attaches to an exo-site, allowing the drug's "head" to remain close as it engages and disengages from the beta ${ }_{2}$ receptor. Salmeterol's slower diffusion to the beta ${ }_{2}$ receptor site is thought to be responsible for its longer onset of action (more than 30 minutes) compared with formoterol (10 minutes) and albuterol (within minutes). It is thought that the $\mathrm{N}$-aralkyl group on formoterol is responsible for the strong beta ${ }_{2}$ receptor selectivity and the formamide group for its intrinsic activity and affinity for the beta receptor. Formoterol is more potent than salmeterol; equipotent doses are thought to be $12 \mu \mathrm{g}$ to $50 \mu \mathrm{g}$, respectively. ${ }^{5}$ In addition, formoterol is a full beta ${ }_{2}$ receptor agonist, while salmeterol and albuterol are partial agonists. This activity at the receptor may explain the smaller maximal effect of salmeterol compared with formoterol. It is not clear if these pharmacologic differences translate into differences in clinical efficacy. ${ }^{5}$ As a class, LABAs are usually well tolerated, but have been reported to cause sinus congestion, rhinitis, headache, and influenza. ${ }^{15}$

Corticosteroids modulate gene expression to decrease the production and release of cytokines and other mediators causing airway inflammation. Corticosteroids also decrease the recruitment of eosinophils to the airways, which further decreases mediator release and inflammation. ${ }^{4}$ While mast cell stabilizers and leukotriene modifiers can also be asthma controller medications, ICS are the preferred long-term controller medication. ${ }^{3,4}$ Usually, ICS are well 
tolerated. The most common adverse reactions are local oral candidiasis, dysphonia, upper respiratory infections, and throat irritation. ${ }^{4,15}$ These can be minimized or avoided by using the lowest possible dose,${ }^{16}$ administering by a holding chamber (with metered-dose inhalers), and rinsing the mouth after use., ${ }^{4,17}$ Using the lowest effective dose of ICS limits long-term drug exposure, thereby minimizing the potential for systemic effects (eg, slower linear growth, decreases in bone mineral density, increase frequency of cataracts or glaucoma). ${ }^{18} \mathrm{FP}$ has properties typical of other ICS agents. The estimated comparisons of "low", "medium", and "high" doses of different ICS (Table 2) are to guide the clinician in titrating the minimal effective dose to achieve and maintain asthma control. The treatment algorithms for adults and children are similar. However, the ICS dose "cut points" for children are slightly lower than for adults. For example, a "low" dose of FP in children younger than 5 years of age is less than $100 \mu \mathrm{g}$ whereas a "low" dose in adults is less than $250 \mu g^{3}$

\section{Data sources}

An initial PubMed and EMBASE search was conducted in July 2014 for clinical trials using the following terms: "fluticasone propionate", "formoterol fumarate", "Flutiform $^{\circledR}$ ", and "asthma", with no time limits. Clinicaltrials.gov was searched utilizing the terms "fluticasone propionate" and "formoterol fumarate". Additional publications were identified by reviewing the references of the included trials and the drug monograph. In evaluating data for inclusion, priority was given to blinded, randomized, controlled studies evaluating efficacy and/or safety. In vitro studies and nonEnglish publications were excluded, as were trials involving animals or subjects with chronic obstructive pulmonary disease. Due to the small number, all identified clinical studies were included. These were all published between 2011 and 2013.

\section{Safety and efficacy trials}

The safety and efficacy of the FP-F combination has been assessed in seven trials. ${ }^{19-24}$ Two of the trials ${ }^{20,22}$ have been summarized in a previous review. ${ }^{25}$ All of these trials assessed subjects who were at least 12 years of age and older. Table 3 summarizes the methodology and results of these trials. Two trials ${ }^{19,22}$ were placebo-controlled, five trials ${ }^{19,20,22-24}$ compared the combination inhaler with its individual components (ie, FP and/or F alone), and two trials ${ }^{21,26}$ compared the combination inhaler with FP plus F administered in two separate devices. All of these ${ }^{19-24}$ were brief, lasting 8-12 weeks.
All had similar inclusion criteria documenting subjects with mild to moderate asthma. The primary efficacy endpoints were change in predose and/or 2 hours post dose $\mathrm{FEV}_{1}$. The combination inhaler product was found to improve $\mathrm{FEV}_{1}$ to a greater extent than placebo, ${ }^{19,22}$ and the individual components ${ }^{19,20,22-24}$ were noninferior to combination therapy administered by separate devices. ${ }^{20,21}$ Other endpoints included: rescue medication use, asthma symptom scores, asthma-control days, symptom-free or rescue medication-free days, sleep disturbances, and awakening-free nights. There were some isolated differences across the studies. In one study, ${ }^{19}$ rescue medicine use and frequency of exacerbations were lower; there were more symptom-free days in the combination group versus placebo. In another, ${ }^{20}$ there were fewer subjects discontinuing therapy in the combination group than with fluticasone alone. In a third study, ${ }^{22}$ there were more rescue-free and symptom-free days versus fluticasone alone. Often however, the differences between the groups for these clinical outcomes were not significant. Across these studies, the adverse effects reported were mild to moderate. The most common adverse effects were nasopharyngitis, pharyngitis, headache, asthma exacerbations, and dysphonia. No laboratory, blood pressure, electrocardiogram, or heart rate abnormalities were reported.

The strengths of these studies were the documentation of asthma by pulmonary function tests prior to study entry and objective exclusion of those with chronic obstructive pulmonary disease, recent exacerbations, or severe asthma. Adherence was generally good (ie, greater than $75 \%$ of doses) assessed by diary or dose counters. ${ }^{19,21-23}$ Device instruction was given and/or device technique assessed prior to study entry. ${ }^{19-21}$ For studies using more than one dose of the ICS, the study ICS dose for an individual subject was determined based on the prestudy ICS dose of the subject. The general lack of differences in clinical endpoints between studies might be explained by varying levels of asthma severity, relatively short duration of the trials, and lack of sufficient numbers of subjects for adequate power to detect differences in secondary endpoints. Overall, the combination of FP-F improved pulmonary function when compared to its individual components and placebo, and was well tolerated.

One open-label trial ${ }^{26}$ involving 465 subjects evaluated the tolerability of the FP-F combination product (either $100 / 10$ or $250 / 10 \mu \mathrm{g}$ ) for a longer period (6-12 months). The incidence of drug-related adverse events was low at only $3.8 \%$, and none were considered serious. The most frequent adverse events $(>2 \%)$ were nasopharyngitis, dysphonia, 


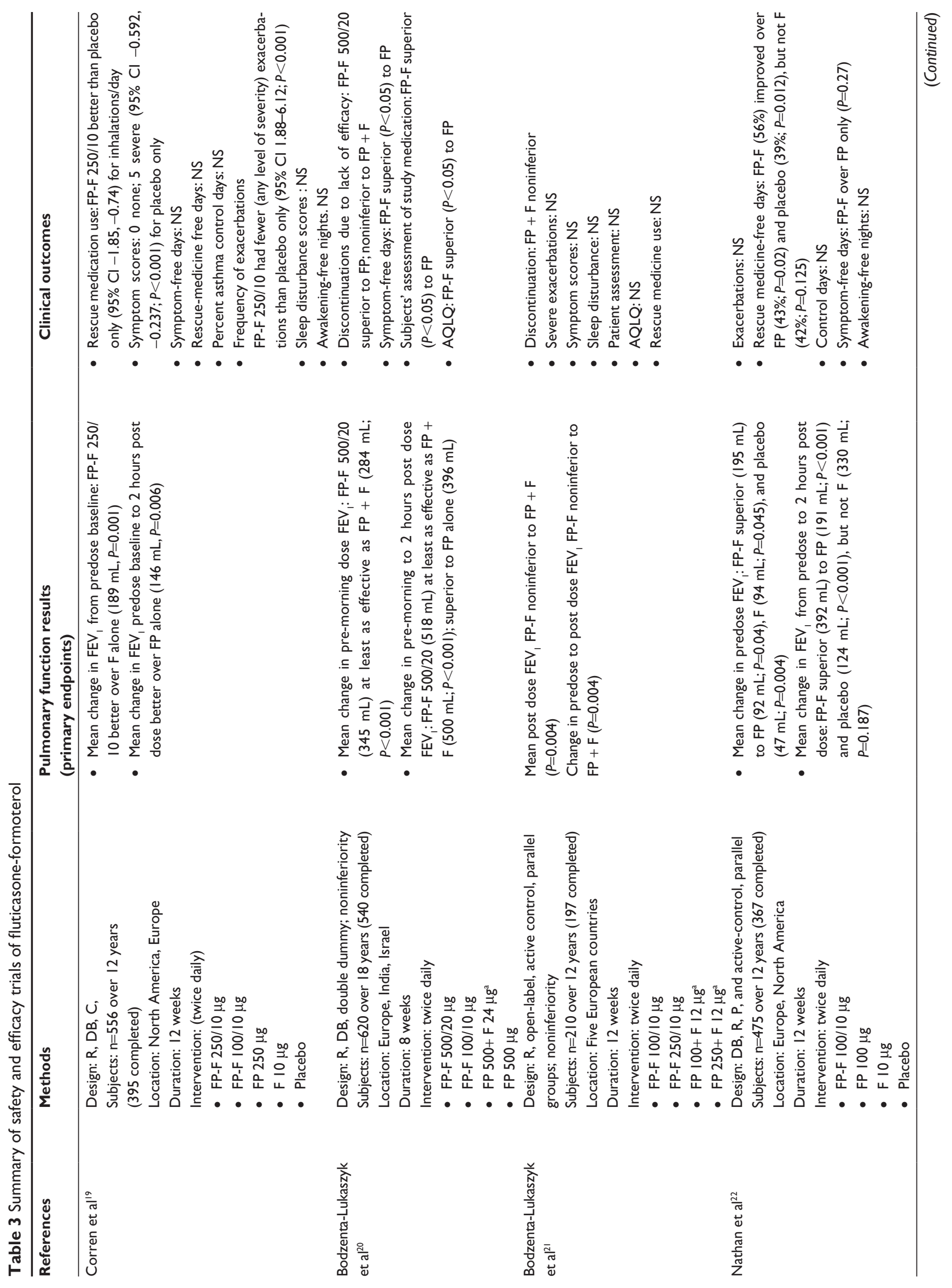




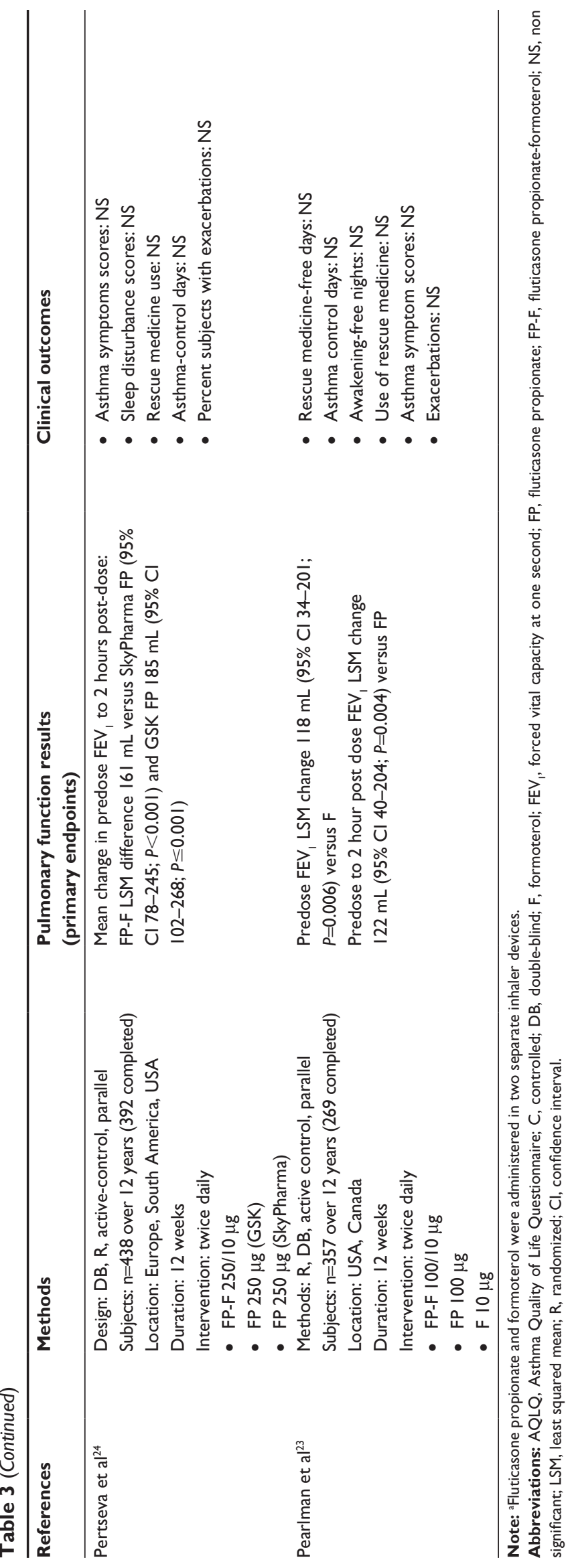

pharyngitis, and headache. No significant differences in laboratory values or vital signs were reported.

\section{Comparison trials of fluticasone- formoterol versus other ICS-LABA combinations}

One 12-week, open-label study ${ }^{27}$ (Table 4) compared FP-F with fluticasone propionate-salmeterol (FP-S) in adult patients with mild to moderately severe asthma. After a screening phase, subjects were randomized to receive either FP-F or FP-S per an HFA inhaler administered with an Aerochamber ${ }^{\circledR}$ holding chamber. The ICS dose was determined by the ICS dose prior to study entry, but those starting at the lower ICS dose could be switched to a higher dose during the study at prescribers' discretion. Subjects were allowed to use up to eight inhalations of albuterol daily as rescue medicine. The primary objective was the comparison of mean predose $\mathrm{FEV}_{1}$ at week 12. Secondary objectives were to compare the time to onset and frequency of discontinuation due to lack of effect, amount of rescue or systemic corticosteroids used, frequency of adverse events, and quality of life scores. Researchers calculated the percentage of adherence by dividing the number of actuations taken by number of actuations that should have been taken.

The results supported FP-F as noninferior to FP-S for the primary endpoint of predose $\mathrm{FEV}_{1}$ at week 12 . There were no differences noted in clinical endpoints, such as symptom scores, sleep scores, and use of rescue medicine. The number of subjects discontinuing the study due to lack of efficacy was not significantly different. The percentage of mild or moderate (10.9\% FP-F, $11.9 \%$ FP-S) and severe (3\% FP-F, $1 \%$ FP-S) exacerbations was similar. The time to onset (first time point post dose with an $\mathrm{FEV}_{1}$ that was at least $12 \%$ greater) favored FP-F. More FP-F subjects met the criterion for onset of action on day 0 at 5 minutes (39\% versus 14\%) and within 2 hours (77\% versus 64\%). A difference in onset was reported at 12 weeks also. More subjects rated the FP-S combination as good or very good, but this difference was not statistically significant.

Adverse events were similar in frequency (23.8\%), type (infections were most frequent, at 13.9\% for FP-F and 12.9\% for FP-S), and severity (one severe event in each group, but neither was considered related to the study medicine). There were no significant changes in serum glucose or potassium, vital signs, or electrocardiograms in the reported results.

The strengths of this study were the well-defined criteria for exclusion of subjects with chronic obstructive pulmonary 


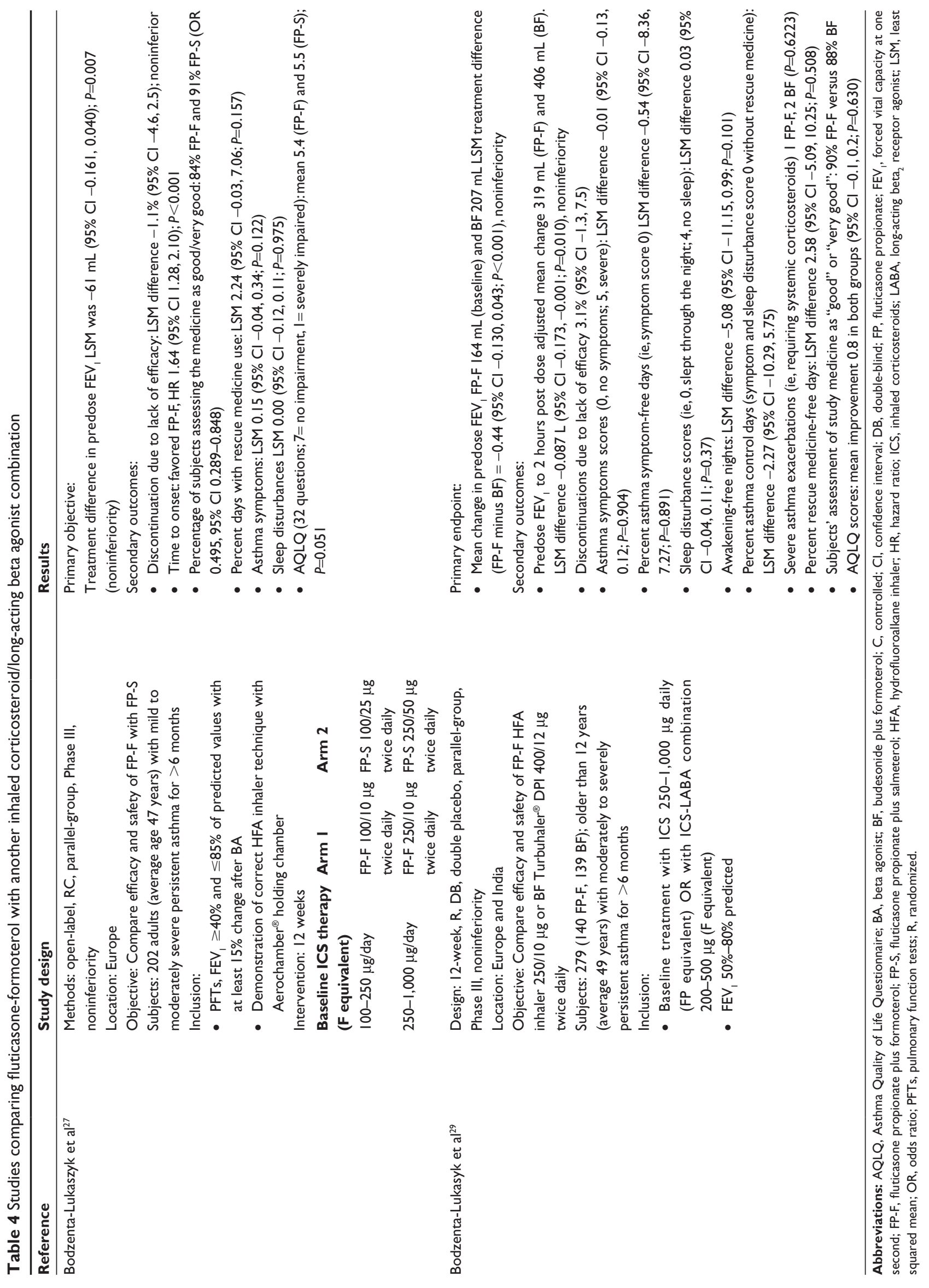


disease and confounding tobacco use. Subjects were stratified by prior dose of ICS. The use of HFA inhalers with a holding chamber for both study medicines and provision of device technique instruction controlled for potential differences in devices and device technique. The researchers clearly defined endpoints, such as criteria for exacerbations and included other clinical efficacy outcomes. Adherence (taking more than 75\% of doses) was high in both groups (98\% and 99\% of subjects). Limitations included the short duration of the study. Also, more men were included in the FP-F arm than the FP-S arm (47\% versus 39\%) and the average of the prior fluticasone equivalent dose was also higher in the FP-F group (500 $\mu \mathrm{g}$ versus $400 \mu \mathrm{g}$ per day). A couple of factors could affect external validity of this study. All subjects were of Caucasian race, and others, such as Asian or black patients, could respond differently. Over $70 \%$ of subjects in both groups were started on the higher dose of ICS. It is possible that there could be differences between these medicines when lower ICS doses are used.

Subsequently, the researchers performed a post hoc analysis of these data to further evaluate differences in speed of onset between FP-F and FP-S. ${ }^{28}$ The odds ratio (OR) of achieving bronchodilation within 5 minutes of a dose were higher in the FP-F group both on day 0 (OR 3.97; 95\% confidence interval [CI] 1.96-8.03) and day 84 (OR 9.58; 95\% CI 2.14-42.9). Those in the FP-F group were more likely to have an onset of bronchodilation within 120 minutes on day 0 (hazard ratio $1.47 ; 95 \%$ CI 1.05-2.73) and also on day 84 (hazard ratio $1.77 ; 95 \% \mathrm{CI} 1.14-2.73$ ). The least square mean change in $\mathrm{FEV}_{1}$ from predose on day 0 favored $\mathrm{FP}-\mathrm{F}(0.112 \mathrm{~L}$; 95\% CI 0.42-0.181; $P=0.002)$ and day $84(0.06 \mathrm{~L} ; 95 \% \mathrm{CI}$ 0.008-0.113). The authors postulate that these data could translate into improved treatment adherence in patients with asthma. However, this interpretation should be accepted cautiously; the overall difference in $\mathrm{FEV}_{1}$ was relatively small and may not translate into a detectable improvement of clinical symptoms. Also, in the original study, ${ }^{27}$ slightly more subjects assessed FP-S as good or very good despite this reported difference in onset.

Only one other ICS-LABA comparison study was found. ${ }^{29}$ A FP-F HFA inhaler $(250 / 10 \mu \mathrm{g}$ twice daily) was compared with budesonide-formoterol (B-F, 400/12 $\mu \mathrm{g}$ twice daily) administered by a dry powder device (Turbuhaler ${ }^{\circledR}$ ). Subjects at least 12 years of age and older with uncontrolled asthma on $200 \mu \mathrm{g}$ daily of fluticasone at the end of a 14-day run-in period were randomized. Up to eight inhalations of albuterol were allowed daily as rescue medicine. Subjects were stratified into each treatment group based on their degree of lung impairment $\left(\mathrm{FEV}_{1}\right.$ over $60 \%$ predicted and $50 \%-60 \%$ predicted). All but ten subjects (six FP-F and four B-F) were taking ICS at study entry (mean dose $500 \mu \mathrm{g}$ FP equivalents) with a mean predicted $\mathrm{FEV}_{1}$ of $66 \%$.

Results support FP-F as being comparable with B-F in terms of the primary endpoint (change in predose $\mathrm{FEV}_{1}$ ) and secondary endpoints including symptom and sleep disturbance scores, percentage of symptom-free days, asthma control days, awakening-free nights, quality of life scores, and subjects' assessment of the medicine (Table 4). Of the 18 subjects discontinuing the study, only eight were due to lack of efficacy (six B-F and two FP-F). There were no changes in serum potassium or glucose, vital signs, or electrocardiograms. The researchers concluded that the effect of FP-F on lung function and other efficacy monitors was comparable with B-F.

The strengths of the study were clear entry criteria for asthma and level of severity. Demonstration of good device technique was required for entry. Those with tobacco use and severe or uncontrolled asthma in the last 4 weeks were excluded. The doses of budesonide and fluticasone were comparable. Adherence was measured (based on the number of actuations recorded in an electronic diary), and $96 \%$ of subjects recorded taking $75 \%$ or more of doses. Criteria for endpoints such as worsening asthma and subject withdrawals were well defined. Many clinical endpoints were evaluated, providing a more robust support for the conclusion of noninferiority.

A limitation was the use of different devices to deliver the study medications. The devices used were based on the availability of the medicine in the countries where the study was conducted. However, checking device technique of subjects prior to study entry limits the impact of this variable. It should be noted that the B-F dry powder inhaler used in this study is not available in some countries (eg, the USA). There was also a slightly higher dose of formoterol in the B-F arm. However, due to the relatively flat dose-response curve of LABA agents, that would not be likely to significantly affect the results. More women were randomized to the B-F group (72.7\% B-F to $62.9 \%$ FP-F). However, the authors noted the post hoc exploratory analysis did not reveal any significant sex differences in the primary outcome. These factors might have been more significant if a difference in outcomes between the study medicines had been noted.

\section{Discussion}

Flutiform $^{\circledR}$ is a relatively new ICS-LABA (FP-F) combination product in the asthma market. Use of a LABA-ICS 
combination is appropriate for patients whose asthma cannot be managed with low-dose ICS monotherapy., ${ }^{3,430}$ Recent reports of serious asthma exacerbations and asthma-related deaths have raised concerns regarding the use of LABAs (especially as single-drug controller therapy). ${ }^{31}$ On the other hand, the results of a recent meta-analysis indicate that stepping down treatment from an ICS-LABA combination to an ICS alone resulted in increased asthma impairment, worsening of asthma quality of life questionnaire scores, and fewer symptom-free days. ${ }^{32}$ It is useful to prescribe a combination ICS-LABA inhaler for those requiring both medications. A combination product minimizes the risk of nonadherence to one inhaler and resulting inadvertent monotherapy with either an ICS or LABA alone.

For patients requiring combination therapy, there are several considerations in selecting the best product. The first and foremost consideration is usually efficacy. At this time, there are no data to suggest that one ICS-LABA combination product is better than another if comparable doses are used. The FP-F combination product is available in three strengths, ${ }^{33}$ ie, $50 / 5 \mu \mathrm{g}, 125 / 5 \mu \mathrm{g}$ for those aged 12 years and older, and $250 / 10 \mu \mathrm{g}$ for those aged 18 years and older. By having multiple strengths available, clinicians may more easily titrate the ICS dose without having to switch to another combination product and potentially switch to another device. This is not an option for all combination products. For example, budesonide/formoterol HFA is only available in two strengths, making it difficult to titrate to a high-dose ICS without going over the usual recommended daily dose of the LABA.

The second consideration in selection of medication is often differences in potential or actual adverse reactions. At this time, there do not appear to be any significant differences in the common adverse reactions between the currently available combination products. In the rare circumstance of a patient with a history of severe milk protein allergy, the FP-F combination product (Flutiform $\left.{ }^{\circledR}\right)^{34}$ or budesonide/formoterol would be preferred because these products currently do not contain lactose. However, clinicians should double-check the most current product information before prescribing in case the product formulation has changed.

With little difference in efficacy or safety, the third consideration is cost. Flutiform ${ }^{\circledR}$ is not yet approved in all major markets (eg, the USA). The pricing in each individual country where it is available likely varies. In general, combination inhaler products are less expensive than the individual agents in separate devices. Patients may also benefit from combination products because of a single copayment versus two copayments (one for each individual product). In choosing between combination products, a lesser acquisition cost could be a deciding factor in institutional formulary decisions.

A fourth important consideration is patient preference for and ability to correctly use the specific drug delivery device. There are significant differences in optimal technique between HFA inhalers and dry powder devices, especially regarding the optimal inhalation rate. Most patients with asthma should be familiar with an HFA inhaler, especially if they already use one for their "rescue" inhaler with a short-acting beta ${ }_{2}$ receptor agonist. Patients with good HFA inhaler technique may prefer to use one of the ICS-LABA HFA inhalers like FP-F (Flutiform ${ }^{\circledR}$ ), so they only have to learn to use one device.

For those patients with inadequate technique (especially for timing of actuation to inhalation), there are two options. Use of a holding chamber with the HFA inhaler is often recommended. If patients elect to use a holding chamber, only those holding chambers documented to be compatible with that particular inhaler should be utilized. If patients are unable to correctly use the Flutiform ${ }^{\circledR}$ HFA inhaler, the AeroChamber Plus ${ }^{\circledR}$ holding chamber is recommended. ${ }^{32}$ An advantage of dry powder delivery devices is that holding chambers are not required to assist with the timing of actuation for inhalation. Patients' dry powder technique may be better than that with HFA inhalers, but poor device technique is still common with the dry powder devices. ${ }^{7}$

Guidelines from the American College of Chest Physicians indicate that potential device-specific differences in drug delivery are less likely to impact efficacy than the correct use of the specific device prescribed. ${ }^{35}$ The recommendation therefore is to select an ICS-LABA product in a device that a particular patient can utilize correctly to optimize drug delivery. Regardless of the product initially chosen, patients should be instructed, periodically reassessed on their device technique, and the results documented in the medical record.

It is useful to have available on formulary products with more than one approved indication as well as products that have been studied in a pediatric population. The manufacturer of FP-F is pursuing a COPD indication in Europe. ${ }^{36}$ Product information does not currently include an indication for children younger than 12 years of age. ${ }^{34}$ Multiple indications would also add to the versatility of this product. 


\section{Conclusion}

The use of an ICS/LABA combination is indicated for the maintenance treatment of patients with asthma that cannot be well controlled on low-dose ICS monotherapy. Available data indicate that FP-F therapy in asthma is comparable in efficacy and safety to other combination products for adults. However, no long-term studies or trials in children younger than 12 years of age are available. The potential for better adherence or improved device technique with FP-F should be considered, especially in individual patients who prefer to utilize an HFA inhaler to administer all medications. However, until there are data documenting improved clinical efficacy or safety versus other ICS/LABA combinations, the deciding factor in patient specific and formulary decisions could be cost.

\section{Disclosure}

The authors received no funding for this review and report no relevant conflicts of interest.

\section{References}

1. Global Strategy for Asthma Management and Prevention, Global Initiative for Asthma. 2014 Appendices. Available from: http://www.ginasthma.org/local/uploads/content/files/GINA_Appendix_2014_Jun11. pdf. Accessed December 10, 2014.

2. Centers for Disease Control and Prevention. Survey reveals growing national impact of asthma. Available from: http://www.cdc.gov/media/ releases/2012/p0515_asthma_impact.html. Accessed December 10, 2014.

3. Global Initiative for Asthma. Global Strategy for Asthma Management and Prevention, 2014. Available from: http://www.ginasthma.org/. Accessed December 10, 2014.

4. Expert Panel Report 3. Guidelines for the diagnosis and management of asthma. Available from: http://www.nhlbi.nih.gov/guidelines/asthma/ asthgdln.pdf. Accessed December 10, 2014.

5. Cazzola M, Page CP, Calzetta L, Matera MG. Pharmacology and therapeutics of bronchodilators. Pharmacol Rev. 2012;64:450-504.

6. Horne R, Price D, Cleland J, et al. Can asthma control be improved by understanding the patient's perspective? BMC Pulm Med. 2007;7:8.

7. Boulet LP, Vervloet D, Magar Y, Foster JM. Adherence: the goal to control asthma. Clin Chest Med. 2012;33;405-417.

8. Fischer MA, Choudhry NK, Brill G, et al. Trouble getting started; predictors of primary medication nonadherence. Am J Med. 2011;124: 1081.e9-1081.e22.

9. Moonie SA, Strunk RC, Crocker S, Curtis V, Schechtman K, Castro M. Community asthma program improves appropriate prescribing in moderate to severe asthma. $J$ Asthma. 2005;42:281-289.

10. Healthy People 2020. Respiratory diseases. Available from: http:// www.healthypeople.gov/2020/topicsobjectives2020/objectiveslist. aspx?topicId=36. Accessed December 10, 2014.

11. Walker J, Winkelstein M, Land C, et al. Factors that influence quality of life in rural children with asthma and their parents. J Pediatr Health Care. 2008;22:343-350.

12. PharmaTimes Digital. SkyePharma's Flutiform finally gets EU 'yes'. Available from: http://www.pharmatimes.com/Article/12-07-04/SkyePharma_s_ Flutiform_finally_gets_EU_yes.aspx. Accessed December 10, 2014.

13. PMLive. Successful partnerships in pharma: Skyepharma and Mundipharma. Available from: http://www.pmlive.com/pharma_news/successful_ partnerships_in_pharma_skyepharma_and_mundipharma_606751. Accessed December 10, 2014.
14. Skypharma.com. Flutiform marketing. Available from: http://www. skyepharma.com/Products/Inhalation_products/Approved_inhalation_ products/Flutiform_marketing/Default.aspx?id=72. Accessed December 9, 2014.

15. Facts and Comparisons. eAnswers. Available from: http://online. factsandcomparisons.com/MonoDisp.aspx?monoID=fandc-hcp12879 $\&$ quick $=650717 \% 7 \mathrm{c} 5 \&$ search $=650717 \% 7 \mathrm{c} 5 \&$ isstemmed $=$ True $\& \mathrm{~N}$ DCmapping=-1\&fromTop=true\#firstMatch. Accessed December 10, 2014.

16. Lipworth BJ. Systemic adverse effects of inhaled corticosteroids: a systematic review and meta-analysis. Arch Intern Med. 1999;159: 941-955.

17. Roland NJ, Bhalla RK, Earis J. The local side effects of inhaled corticosteroids. Current understanding and review of the literature. Chest. 2004;126:213-219.

18. Facts and Comparisons. eAnswers. Available from: http://online. factsandcomparisons.com/MonoDisp.aspx?monoid=fandc-hcp12443 $\&$ book $=$ DFC \& fromtop=true $\&$ search $=375422 \% 7 \mathrm{c} 5 \&$ isStemmed $=$ Tru e\&asbooks=. Accessed December 10, 2014.

19. Corren J, Mansfield LE, Pertseva T, Blahzko V, Kaiser K. Efficacy and safety of fluticasone/formoterol combination therapy in patients with moderate-to-severe asthma. Respir Med. 2013;107;108-95.

20. Bodzenta-Lukaszyk A, Pulka G, Dymek A, et.al. Efficacy and safety of fluticasone and formoterol in a single pressurized metered dose inhaler. Respir Med. 2011;105:674-682.

21. Bodzenta-Lukaszyk A, van Noord J, Schroder-Babo W, McAulay K, McIver T. Efficacy and safety profile of fluticasone/formoterol combination therapy compared to its individual components administered concurrently in asthma: a randomized controlled trial. Curr Med Res Opin. 2013;29:579-588.

22. Nathan RA, D'Urzo A, Blazhko V, Kaiser K. Safety and efficacy of fluticasone/formoterol combination therapy in adolescent and adult patients with mild-to-moderate asthma: a randomized controlled trial. BMC Pulm Med. 2012;12:67-82.

23. Pearlman DS, LaForce CF, Kaiser K. Fluticasone/formoterol combination therapy compared to monotherapy in adolescent and adult patients with mild to moderate asthma. Clin Ther. 2013;35:950-966.

24. Pertseva T, Dissanayake S, Kaiser K. Superiority of fluticasone propionate/formoterol fumarate versus fluticasone propionate alone in patients with moderate-to-severe asthma: a randomized controlled trial. Curr Med Res Opin. 2013;29:1357-1369.

25. Dissanayake S, Grothe B, Kaiser K. Fluticasone/formoterol: a new single-aerosol combination therapy for patients with asthma. Respir Med. 2012;106:520-528.

26. Mansur AH, Kaiser K. Long-term safety and efficacy of fluticasone/ formoterol combination therapy in asthma. J Aerosol Med Pulm Drug Deliv. 2013;26:190-199.

27. Bodzenta-Lukaszyk A, Dyrnek A, McAulay K, Mansikka H. Fluticasone/formoterol combination therapy is as effective as fluticasone/salmeterol in the treatment of asthma, but has a more rapid onset of action: an open-label, randomized study. BMC Pulm Med. 2011;11: $28-38$.

28. Aalbers R, Brusselle G, McIver T, Grothe B, Bodzenta-Lukasyk A. Onset of bronchodilation with fluticasone-formoterol combination versus fluticasone-salmeterol in an open-label, randomized study. $A d v$ Ther. 2012;29:958-969.

29. Bodzenta-Lukasyk, Buhl R, Balint B, Lomax M, Spooner K, Dissanayake S. Fluticasone/formoterol combination therapy versus budesonide/formoterol for the treatment of asthma: a randomized, controlled, non-inferiority trail of efficacy and safety. J Asthma. 2012;49: 1060-1070.

30. Kramer JM. Balancing the benefits and risks of inhaled long-acting beta-agonists - the influence of values. $N$ Engl J Med. 2009;360: 1592-1595.

31. Chowdhury BA, Pan GD. The FDA and safe use of long-acting beta-agonists in the treatment of asthma. $N$ Engl J Med. 2010;362: 1169-1171. 
32. Brozek JL, Kraft M, Krishnan JA, et al. Long-acting $\beta 2$-agonist stepoff in patients with controlled asthma. Systematic review with metaanalysis. Arch Intern Med. 2012;172:1363-1373.

33. National Institute for Health and Care Excellence. Evidence summary. Available from: http://www.nice.org.uk/advice/esnm3. Accessed November 18, 2014.

34. Napp Pharmaceuticals Ltd. Flutiform ${ }^{\circledR}$ package insert. Available from: https://www.medicines.org.uk/emc/PIL.26957.1atest.pdf. Accessed December 10, 2014.
35. Dolovich MB, Ahrens RC, Hess DR, et al. Device selection and outcomes of aerosol therapy: evidence-based guidelines. Chest. 2005;127: 335-371.

36. Skypharma. Annual Report and Accounts 2013. Available from: http://www.skyepharma.com/Doc/02_PDF/01_FINANCIAL\%20 INFORMATION/2013\%20Annual\%20Report.pdf. Accessed December 10, 2014.

\section{Publish your work in this journal}

Therapeutics and Clinical Risk Management is an international, peerreviewed journal of clinical therapeutics and risk management, focusing on concise rapid reporting of clinical studies in all therapeutic areas outcomes, safety, and programs for the effective, safe, and sustained use of medicines. This journal is indexed on PubMed Central, CAS,
EMBase, Scopus and the Elsevier Bibliographic databases. The manuscript management system is completely online and includes a very quick and fair peer-review system, which is all easy to use. Visit http://www.dovepress.com/testimonials.php to read real quotes from published authors.

Submit your manuscript here: http://www.dovepress.com/therapeutics-and-clinical-risk-management-journal 